Kooyman and they cover the field concisely and well. The sections on blood (Claude Lenfant), cardiovascular adjustments to diving (Robert Elsner) and temperature regulation (Laurence Irvine) are fascinating discussions. It is these fields that have fascinated so many physio. logists. Any mammal that has to cope with such a foreign environment as the sea for its everyday life has an enormous problem. Although there are similarities, Pinnipedia and Cetacea often tackle the problem differently. For instance, when a seal dives circulation is limited to essential organs such as the brain, in a far more dramatic way than in the Cetacea. But experimental work in this field is difficult, as is shown in this book. Early work on diving seals had shown a dramatic reduction in heart rate to something in the order of $1 / 12-1 / 18$ of that of the surface: fright could also induce this effect. In more recent experiments using trained seals to dive freely, rather than being forcibly dunked, the respiratory rate, although markedly reduced, was of the order of 18-25 beats a minute instead of 6-8. In porpoises, the effect of restraining compared with free swimming was even more dramatic. A free dive led to a drop of some 90 down to 12 beats a minute later increasing to 20 beats per minute, but forced diving a porpoise may lead to death, the animal refusing to breathe again.

It is hardly surprising that the brain of such intelligent creatures as dolphins should have been studied with enthusiasm and be so well reported by Jan and J. K. S. Jansen, who have done such outstanding work in the field, but unfortunately the other marine mammals are neglected, though work has been done on the brains of seals admittedly to a much smaller extent. Echolocation (Kenneth Norris) is also a field of activity in which a highly developed brain is important. Such observations as the superior olive being highly developed in both the main users of echo-location, Cetacea and bats, must obviously stimulate new interest in the neurophysiology and anatomy of this field. That the temporal lobes should be highly developed as acoustic analysers is a logical expectation.

Echo-location is not only a fascinating zoological study but one with wide human interests as well in naval research. Whiether the Pinnipedia use echo-location still remains unproven; there is good possibility, but at its best it must be of a much lower quality than the dolphins and more difficult to prove effectively.

The more social aspects of communication and other ecological factors are well treated by W. E. Evans and Jarvis Bastian. They have had a difficult task collecting information of widely different character, and they make an effective contribution. R. J. Harrison has also made an excellent compilation of the reproductive and endocrine systems, a field in which he has made outstanding advances himself.

In general, this book, with its specialist authors, does as the editor intended and can be highly recommended. But, equally, an editor should attempt to bring all his chapters up to the same level and it is unfortunate that an early chapter should be well below the level of the others.

K. M. Backhouse

\section{IRREGULAR ECHINOIDS}

The Systematics of Sympatric Species in West Indian Spatangoids

A revision of the Genera Brissopsis, Plethotaenia, Paleopneustes, and Saviniaster. By Richard H. Chesher. (Studies in Tropical Oceanography No. 7.) Pp. vii + $168+35$ plates. (University of Miami Press: Coral Gables, Florida, January 1969.) $\$ 12$.

ALthough this study deals primarily with only ten species of irregular echinoids from the east and west tropical Atlantic, many of the implications arising from it are applicable to the world-wide problem of the interrelationship and distinction of sympatric species (affiliated species occupying the same habitat). In addition, the detailed accounts of growth changes and their effects on taxonomic characters, notably those based on the fascioles or belts of fine ciliated spines and the part these play in life, are relevant to the study of the biology and taxonomy of spatangoids in general. The descriptive format for echinoids in current use is mainly that developed by Mortensen, which included tabulations of plate numbers and relative proportions of apical system and peristome as well as whole test measurements for regular echinoids but rarely more than the last for the irregular forms. Chesher, however, has developed elaborate statistical tables based on at least forty precise measurements and counts derived from each specimen, including even estimates of fasciole length achieved by "walking" along them with dividers, which is possibly more accurate though surely more time-consuming than the usual twisted string method for measuring devious lengths. Because he was able to base his studies on extensive new collections of tropical echinoids, including over two hundred specimens of one species and at least twenty-five of seven others, at an estimated time of 15-20 minutos for each specimen an impressive total of basic work has clearly been done. Analysis of the resultant figures has brought him to the conclusion that there are two sympatric species of both Plethotaenia and Paleopneustes in the tropical Atlantic where only one of each was previously thought to occur. The implication from this is that if the same high standard of detailed examination were applied to other spatangoids still more new species are likely to be established. Unfortunately, there is but a single specimen of the new species which Chester refers to the little-known genus Saviniaster, previously recorded only from the Eocene of France and based on poorly-preserved material which prohibits a proper comparison. The inclusion of this is not really relevant to the main study of the book. Some rearrangement of the genera and species involved is carried out and their relationships with other spatangoids discussed. There are also some interesting notes on the habitats and behaviour of some of the species, notably of Brissopsis, adding to the literature on this subject initiated largely by Nichols. The illustrations consist mainly of numerous photographs showing growth changes and entire and denuded tests, as well as enlargements of details such as pedicellariae and tube feet, some of which might have been more clearly represented by drawings. Apart from this small criticism, I think Chesher is to be congratulated for setting a new high standard for the treatment of this interesting group of animals.

Ailsa Clark

\section{FUNGAL GUIDE}

\section{A Pictorial Guide to the Identification of Fusarium Species according to the Taxonomic System of Snyder and Hansen}

By T. A. Toussoun and Paul E. Nelson. Pp. 51. (Pennsylvania State University Press: University Park, and London, April 1969.) $56 s 6 d$.

EXPERTs accepting different systems of classification of species of Fusarium differ very greatly in the number of species which they recognize. For example, Wollenweber and Reinking recognized sixty-five species, fifty-six varieties and twenty-two forms, whereas Snyder and Hansen recognize nine species with no varieties but use formae speciales to denote pathogenicity to plant species or groups of plant species. Other present day workers accept that several morphological types should be recognized within some of the nine species recognized by Snyder and Hansen although the number of species worthy of recognition is 